\title{
Permanente homoseksuele verhoudings van liefde en trou
}

\author{
J Potgieter $^{1}$ \\ (Universiteit van Pretoria)
}

\section{ABSTRACT \\ Permanent homosexsual relationships of love and commitment}

In this article, the argument is made that homosexual relationships of love and commitment was known by the writers of the Bible. Though definitions like "gay" or "homosexuality" was not known, sexual identity was known. According to the anthropology of the Mediterranean people, somebody's identity was found in the way he or she lived: "If I have a homosexual relationship, then my identity was homosexual".

This article shows that permanent homosexual relationships of love and commitment were known among the Greek philosophers. People like Plato, Aristotle and Pausanius had permanent homosexual partners. Even Paul knew about permanent homosexual relationships of love and commitment. Sufficient evidence has been found in cities like Rome, Corinth and Ephesus on the existence of such relationships.

Die debat rakende seksuele homoseksuele verhoudings is vandag een van die kerndebatte in die kerk en die media. Voorstanders van permanente homoseksuele verhoudings van liefde en trou argumenteer graag dat die Bybelskrywers nie die "tipe" homo-eksualiteit wat vandag bestaan, geken het nie. Die homoseksualiteit waarvan die Skrif praat, is volgens hulle perverse seksuele verhoudings of homoseksuele verhoudings wat in die kultusse voor gekom het. Baie word daarvan gemaak dat die begrip "homo-eksualiteit" of "homoseksueel" 'n relatiewe jong term is. Dit is eers in 1892 in Duitsland die eerste keer gebruik. Dit is volgens hierdie groep nie afgelei van die Latyn homo (man/mens) nie, maar vanuit die Grieks homoios (dieselfde) wat dus dui op 'n seksuele oriëntasie vir dieselfde geslag (O’Via 2003:1). Dit impliseer dat die debat in groot mate gevoer word oor die seksuele identiteit van homoseksuele persone met die

1 Artikel gebaseer op doktorale proefskrif onder leiding van Prof J G van der Watt, Departement Nuwe Testamentiese Wetenskap, Universiteit van Pretoria, as promotor. 
argument dat die skrywers van die Bybel nié 'n homoseksuele oriëntasie geken het nie.

\section{OP SOEK NA ' $N$ SEKSUELE IDENTITEIT}

\subsection{Homoseksuele oriëntasie is ' $n$ onbekende vir Bybel- skrywers}

Homoseksualiteit is dus volgens hierdie groep eerder "vreemde seksualiteit" of "grys seksualiteit" (Barnard 2000:84-86). Dit is ' $n$ manier van seksuele uitlewing en gee ruimte vir 'n "alternatief" op heteroseksualiteit. Anthonissen en Oberholzer (2001) verduidelik dat die begrippe homoseksualiteit en/of gay-wees daardie "seksuele oriëntasie" is wat verwys na liefde, emosionele betrokkenheid, seksuele aangetrokkenheid en gedrag tussen mense van dieselfde geslag (Anthonissen \& Oberholzer 2001:35-36). "Oriëntasie” of "disposisie" dui op "n bio-psigo-sosiale toestand wat daartoe lei dat iemand hom of haarself as homoseksueel sien (SKLAS Nederduitse Gereformeerde Kerk Wes-en-Suid-Kaapland $2004=$ Predikante konferensie). Dit gaan dus daarom dat iemand se bestaanswerklikheid (eksistensiële gegewe) só is dat die persoon hunker na iemand van dieselfde geslag (Christian Reformed Church in North America 1973/1999:7-9). Dit korreleer met die selfbeeld, selfverstaan en liggaamsbeeld van dié spesifieke persoon (Konsepverslag van SKLAS vir voorlegging aan die Sinode van Wes-en-Suid-Kaapland 1999:2; Werkgroep in verband met homoseksualiteit van die Sinode van die Nederduitse Gereformeerde Kerk van Oos-Transvaal, 2001). Die implikasie van hierdie argument is dat daar dus drie vorme van ' $n$ seksuele oriëntasies bestaan is, naamlik manlik, vroulik en homoseksueel.

' $\mathrm{n}$ Basiese fout deur voorstanders van bogenoemde argument is dat daar teen "begrippe" of "definisies" vasgekyk word. "n Beter metode sal eerder wees om vas te stel hoe seksuele identiteit in die samelewing van die destydse Bybelskrywers beleef is.

\subsection{Homoseksuele identiteit}

Die hipotese in hierdie artikel is dat dit ' $n$ verkeerde argument is om te beweer dat die destydse mense nie 'n homoseksuele oriëntasie geken het nie, bloot omdat die begrippe ("gay" of "homoseksuele oriëntasie”) nie destyds bekend was nie. Dit sal ek doen deur te soek na " $n$ "seksuele identiteit" wat voortgespruit het uit ' $n$ bepaalde gedrag. In terme van die destydse mense sou dus gesê word dat indien permanente homoseksuele verhoudings van liefde en trou 
tussen mense van dieselfde geslag voorgekom het, hulle wel kennis gehad het van wat ons vandag 'n homoseksuele oriëntasie sou noem. Dit moet verstaan word binne die antropologie van die destydse Mediterreense mense, waar iemand se identiteit deur sy/haar optrede bepaal is, met ander woorde "hoe ek optree, is wie ek is" (Malina 1986:26).

In die res van hierdie artikel wil ek poog om aan te toon dat die Griekse en Romeinse kulture wel 'n homoseksuele identiteit (oriëntasie) geken het.

\section{SEKSUALITEIT IN DIE KULTURE VAN DIE DES- TYDSE MEDITEREENSE MENSE}

Seksuele identiteit kom wel in die destydse Griekse en Romeinse kulture na vore. Dit word afgelei uit die seksrolle wat mans en vroue onderskeidelik gespeel het. Seks is gesien as iets wat jy aan iemand anders doen. Die seksrol van die man het gedui op sy aktiewe beheer van die vrou. Die vrou was weer die passiewe ontvanger wat genot geput het om seks te ontvang. Die man "penetreer" en die vrou word "gepenetreer". Owerspel deur 'n vrou (vgl ook Matt 5:31) was verkeerd aangesien sy beheer oor haar eie seksrol geneem het onder die beheer van haar man uit (Karros 2001:1255-1256).

Die vraag rondom seksuele identiteit is dan: Hoe het die gepenetreerde dan sy rol in die verhouding verstaan. Die seksuele identiteit van die manlike homoseksueel word gevind in die feit dat die passiewe persoon die "begeerte" het om deur " $n$ "ander man" gepenetreer te word. Dit is met ander woorde dieselfde begeerte wat by ' $n$ vrou bestaan. Nie alle volwasse mans is as "ware mans" gesien nie. Die passiewe vennoot in die seksuele verhouding is gesien as iemand met ' $n$ "vroulike ervaring" en daarom nie as ' $n$ ware man nie (Karros 2001:1259-1261).

\subsection{Permanente homoseksuele verhoudings in die Griekse kultuur}

Die bestaan van ' $\mathrm{n}$ homoseksuele identiteit word vervolgens ondersteun deur filosowe wat hul voorkeur en liefde vir mans nie weggesteek het nie. Daar word beweer dat onder hierdie filosowe mense soos Sokrates, Cartulles, Virgilius en Horatio was. Dit word afgelei vanweë hul erotiese gedigte oor mans (Verslag van die kommissie Leer en Aktuele sake van die Sinode van Noordkaapland 2003:29). 
In ' $n$ artikel waarin gepoog word om aan te toon dat die verskillende vorme van homoseksualiteit wat vandag voorkom, 'n ou verskynsel is, wys Nassbaum (2002) vanuit die antieke artefakte, toesprake van filosowe, gedigte sowel as Griekse komedies dat mense in die antieke tyd wel homoseksuele verhoudings gehad het waar liefde-en-trou betrokke was. Sy gebruik die Griekse praktyke van homoseksualiteit om daardeur vir die samelewing van vandag meer empatie te laat kry vir die vrese, hoop en vreugde van mense wat persone van dieselfde geslag liefhet (Nussbaum 2002:16-19).

Liddel en Scott (1983) dui aan dat die antieke filosowe spesifieke begrippe gehad wanneer hulle na pederastie ('n volwasse man wat 'n seksuele verhouding met ' $n$ jong seun het) verwys. So is paidarasths/paidikhn gebruik. Dit hou ook verband met die begrip pedofiel $\mathbf{p}$ a idof $\mathrm{il}$ ew wat ook gebruik is om hierdie gebruik aan te toon (Liddel \& Scott 1983:584).

Vanuit die geskrifte van die antieke filosowe is dit billik om te sê dat dit nie ' $n$ korrekte persepsie is dat pederastie en militêre homoseksualiteit die enigste bekende vorme van homoseksualiteit in die destydse antieke samelewings was nie. Wat vandag as kernhomoseksualiteit bekend staan, het ook as ' $n$ aparte seksuele identiteit in die destydse samelewing gefunksioneer.

Hierdie verskynsel kom veral voor in ' $n$ lyn van filosowe waar die een die ander vroeër opgelei het. Dit word gevind by Sokrates, sy student Plato en dié se student, Aristoteles. Plato vertel in sy Symposium (Plato 1995a:36:93) dat Alicibiades op Sokrates verlief was, maar dat Sokrates op daardie stadium 'n permanente verhouding met Agaton gehad het. Alicibiades probeer dan die verhouding tussen Sokrates en Agaton opbreek (Plato 1995a:90:93).

Verder vertel die karakter Aristofanes ('n denkbeeldige skepping van Plato) dat alle mense op soek is na die ander helfte van ons menswees. Hierdie ander helfte is vir sommige mans ander mans, terwyl dit weer vir sommige vroue ander vroue is. Dan is daar ook diegene vir wie hul ander helfte mense van die teenoorgestelde geslag is. In ' $\mathrm{n}$ poging om hierdie gebruik wat oënskynlik volgens hom deur die samelewing as ' $\mathrm{n}$ skandelike praktyk beskou is, aanvaarbaar te maak, skryf Plato apologeties dat sulke permanente verhoudings tussen mense van dieselfde geslag nie skandelik is nie, aangesien hierdie mense hul helfte (wat van dieselfde geslag as hulle is) in vriendskap, liefde en intimiteit soek (Nussbaum 2002:10). 
In gevalle waar ' $n$ man se ander helfte, nog ' $n$ man is, of ' $n$ vrou se ander helfte nog ' $n$ vrou is, sal hierdie mense nie met mense van die teenoorgestelde geslag trou nie ${ }^{2}$. Indien hulle trou (heteroseksueel) is dit net omdat die "wet" dit van hulle vereis. Hulle sou dan eerder verkies om lewenslank by mekaar (mense van dieselfde geslag) te bly op grond van wedersydse liefde, vriendskap en intimiteit. Dit is nie net die seksuele drang wat hulle na mekaar dryf nie, maar ' $n$ intense onbekende onverklaarbare soeke van hulle "siele” na mekaar (Plato 1995b:75).

Dit is daarom ' $n$ billike afleiding om te maak dat daar in die destydse samelewing nie nét homoseksuele verhoudings wat pervers, kulties en pederasties van aard was, voorgekom het en bekend was nie. Permanente langtermyn verhoudings van liefde en trou was bekend. Dit is ook nie sò dat die destydse filosowe net losbandig was nie. Sketse op artefakte dui nie net jonger seuns en ouer mans aan nie, maar ook gevalle waar die sogenaamde jonger persoon inderdaad ouer as "seun-wees" is. Plato se langtermyn verhouding met Dion van Sirakuse het begin toe Plato 50 jaar oud was en Dion 35 jaar. Sommige Stoïsynse filosowe verkies dat verhoudings tussen mense van dieselfde geslag ten minste 28-jaar sou duur (Paulus was bekend met die stoïsynse filosofie aangesien dit waarskynlik een van die sterkste filosofiese strominge in Tarsus was). Pausanias, die spreker in Plato se Symposium, is ' $n$ historiese figuur. Sy homoseksuele verhouding met ' $\mathrm{n}$ digter het vir ten minste 12 jaar geduur. Die verhouding het begin toe ' $\mathrm{n}$ Agaton (Pausanius se homoseksuele lewensmaat en nie dieselfde as die Agaton met wie Sokrates ' $n$ permanente homoseksuele verhouding gehad het nie) 'n volle 18 jaar oud was (Nussbaum 2004:16; Plato 1995b:7:56; Quast 1994:35).

Daar was dus in sekere homoseksuele verhoudings wel sprake van wederkerigheid, duursaamheid en liefde. Die Griekse filosowe wat homoseksualiteit as aanvaarbaar gesien het, het die norm van stabiliteit, vriendskap en liefde bo onstabiele losbandigheid verkies. Beide Plato en Pausanius verwys na hulle homoseksuele verhoudings binne die konteks van ' $n$ lewenslange vennootskap. Waar seks tussen heteroseksuele tot voortplanting kon lei, was seks tussen

2 Die filosoof verwys hier na 'n huwelik binne die konteks van 'n man en 'n vrou. Hy wys egter wel dat mense wat na dieselfde geslag smag hoewel hulle nie met mekaar trou nie, wel in langtermyn verbintenisse met mekaar gaan. 
mense van dieselfde geslag beskou as die voortplanting van dieselfde of " $n$ beter "gees". In Sparta is koormusiek ontdek wat die liefde tussen vroue besing. Plato vertel ook dat die Atheners bekend was met die liefde tussen vroue (Nussbaum 2004:14-17). Die bestaan van langtermyn homoseksuele verhoudings behoort gesien te word binne die konteks dat die Grieke er $\mathbf{0}$ (passie) alleen as iets gewelddadig, chaoties, gevaarlik en onbeheerbaar gesien het. Daar moes ander elemente van wat in Afrikaans as "liefde" beskryf word, ook teenwoordig wees (Karros 2001:1258). Interessant is dat Plato ten spyte van sy eie voorliefde vir ' $\mathrm{n}$ man, in sy Laws erken dat gemeenskap tussen ' $n$ man en ' $n$ vrou natuurlik is, terwyl seks tussen ' $n$ man en ' $n$ man of ' $n$ vrou en ' $n$ vrou nie natuurlik is nie, met ander woorde "teen die natuur" (Plato 1995c:24:611 - p a r a f us in - kon Paulus dit in gedagte gehad het in sy skrywe van Romeine 1?). Later verwys sy gespreksgenoot, 'n onbekende Athener, dat dit beter sou wees dat wette gemaak word om seks tussen mans met mekaar en vroue met mekaar te verbied. Die vraag kan dus met reg gevra word of hierdie interne spanning by Plato rakende homoseksuele verhoudings, beteken dat die antieke mense ook oor die voorkoms van ' $n$ "homoseksuele identiteit" gedebateer het? (Plato 1995c:381: 611).

Karros beweer dat Aristoteles ook positief was oor beide manlike en vroulike homoseksuele verhoudings waar wederkerigheid en liefdesvriendskappe teenwoordig was. Volgens haar sien hy heteroseksuele- en homoseksuele verhoudings nié slegs binne die konteks van die "selfbevrediging van die enkeling se luste" nie. Aristoteles se geskrifte dui vir haar nie daarop dat die antieke Grieke die aktiewe manlike persoon in ' $n$ homoseksuele verhouding as ' $n$ homoseksueel sou sien nie, maar die passiewe vennoot wat genot vind om "gepenetreer" te word - met ander woorde die penetreerder bly “man" (Karros 2001:1257). Die passiewe vennoot in die seksuele verhouding identifiseer met "vroulikheid", terwyl die manlike persoon weer dié persoon is wat die aktiewe seksgenoot is wat sy semen in die passiewe vennoot stort (Aristoteles 1995:56: 286). Vir hom is beide die vorme van seksualiteit onder mans en vroue prysenswaardig as dit binne die konteks van wederkerigheid aan mekaar se behoeftes in langtermyn verhoudings voldoen (Nussbaum 2002:21).

Aristoteles se positiewe siening van liefde vir dieselfde geslag kan verstaan word wanneer hy verduidelik dat daar in die mensdom 
sekere "disposisies" is waarmee mense gebore word. Onder hierdie disposisies is ook seksuele disposisies wat volgens "normale seksuele norme" as "onnatuurlik" (dalk weer Paulus se agtergrond en siening van homoseksuele verhoudings in Rom 1) gesien kan word. Dit is waar ' $n$ man die passiewe rol van die vrou in seksuele dade inneem. Hy skryf:

Now corresponding to each of these kinds of unnatural pleasures ( $f$ i i w) we may observe a related disposition of character. ... These practices result in some cases from natural disposition, and in others from habit, as with those who have been abused from childhood. When nature ( $f$ i $w$ ) is responsible, no one would describe such persons as showing unrestraint, any more than one would apply that term to women because they are passive and not active in sexual intercourse ...

(Aristoteles 2000:1148b).

Uit die antieke geskrifte is ook getuienis gevind dat sekere manspersone in die openbaar as verfynde vroulike (homoseksuele) persone verskyn het. Liddel en Scott wys ook dat die begrip é no S met fyn of verfyn (Aristoteles 2000:1148b; Liddel \& Scott 1983:218), terwyl neanikos weer met homoseksueel vertaal kan word (Liddel \& Scott 1983:218).

Vervolgens wil ek wys op getuienis wat daarop dui dat permanente homoseksuele verhoudings van liefde en trou (homoseksuele huwelike) wel gedurende die tyd van die Nuwe Testament bekend was.

\subsection{Seksualiteit in die Romeinse kulture}

Anders as wat voorstanders van permanente seksuele homoseksuele verhoudings en -huwelike graag wil glo, was permanente homoseksuele huwelike van liefde en trou inderdaad gedurende die tyd van Paulus bekend. Dit het ook voorgekom in al drie die stede aan wie se Christene hy in sy briewe teen die sonde van homoseksuele verhoudings waarsku.

Boswell (1996), 'n homoseksuele persoon en aktivis ten gunste van homoseksuele huwelike van wederkerigheid, duursaamheid, liefde en trou, gee in ' $n$ poging om op die normaliteit van homoseksuele huwelike en seksuele verhoudings te dui, bewyse uit die antieke bronne van sulke huwelike in die destydse Meditereense samelewing waaronder die meeste uit die tyd van Paulus dateer. Dit is verhou-dings waar pederastie, losbandigheid en perversiteit nié ter 
sprake is. Paulus se uitsprake ten opsigte van die gemeentes in Rome, Korinte en Efese (1 Timoteus) moet binne hierdie konteks beoordeel word. In Boswell se bewyse word al hierdie stede genoem:

- $\quad$ Nero het met twee mans in die openbaar in die huwelik getree. Een van hierdie lewensmaats van hom is dan ook as "koningin" vereer (Boswell 1996:69,82-84). Dit is belangrike inligting wanneer die interpretasie van die briewe aan die Romeine, Korinte en Efese bestudeer word. Paulus het hierdie briewe geskryf gedurende die tyd van Nero se regering (54-68 nC) Die Romeine brief waarskynlik in 55-56 nC, die brief van Korinte waarskynlik in 54 nC en 1 Timoteus waarskynlik 61-64 nC (Van der Watt 2003:706, 723, 805).

- Xenophon van Efese vertel van homoseksuele verhoudings van liefde en trou in dié stad. ' $n$ Voorbeeld hiervan is Hippotoos. Hy het ' $n$ man van dieselfde ouderom (nié pederastie nie) as hy liefgehad (Boswell 1996:86; Smith 1996:234). So was die eerste groot liefde van Dionysius, ' $n$ ander man met die naam van Ampelus (Boswell 1996:85).

- Hadrianus (ongeveer $130 \mathrm{nC}$ ) word beskou as een van die vyf beste keisers van Rome. Hy het 'n permanente verhouding met 'n ander man, Antonius gehad (Boswell 1996:85).

- Daar is ook voorbeelde van biseksualiteit. Amatorius, ' $n$ jong man was verlief op beide jongmeisies en jongmans wat dieselfde ouderdom as hy was (Boswell 1996:86).

- Twaalf Attiese vase is gevind met verskillende voorbeelde van volwasse homoseksuele verhoudings (Huppert 1988: 255-268; Smith 1996: 234).

- Daar is nie baie bewyse van lesbiese verhoudings in Rome nie. Boswell motiveer dit aangesien die meeste Romeinse geskiedskrywers manlik was. Daar is wel 'n verhaal wat die skrywer Ovid neergeskryf het van twee vroue wat in 'n liefdesverhouding met mekaar gestaan het (Boswell 1996:83; Brooten 1996:42-45).

- Uit die stad Lesbos is lesbiese erotiese gedigte van Sappho gevind rakende haar sensuele begeertes vir 'n ander vrou (Brooten 1996:29; Smith 1996:234). 
- Lucian vertel in sy Dialogues of the Courtesans van vroue uit die stad Lesbos (waarskynlik waar die benaming lesbies vandaan kom?) wat permanente verhoudings met mekaar gehad het. So is ene Megilla met ' $n$ vrou van Korinte getroud (Boswell 1996:83; Brooten 1996:51-52).

- Plutarch dui op lesbiese verhoudings wat in die stad Sparta voorgekom het (Smith 1996:240).

- Pseudo Phocilydes verwys na die onaanvaarbaarheid van beide manlik en vroulike homoseksuele verhoudings. Die werk dateer ongeveer uit $30 \mathrm{vC}$ tot $40 \mathrm{nC}$.

- Hy vertel ook van ' $\mathrm{n}$ permanente verhouding wat later op ' $\mathrm{n}$ huwelik tussen die koningin van Egipte, Bernice, en 'n vrou van Mesopotamië uitgeloop het:

... rescued her and returned her to her Bernice, from whom she had been taken, and who had become the queen of Egypt after her father's death. Bernice married Mesopotamië (verwysende na die vrou uit Mesopotamië),

(Boswell 1996:84; Brooten 1996:50-51).

- Clement van Alexandrië, 'n Christen kerkvader uit die 2de eeu $\mathrm{nC}$ vertel van vroue wat in lesbiese verhoudings betrokke was. Hy vertel dat hierdie vroue sò openlik oor hulle verhouding van liefde en trou was, dat hulle "teen hul natuur" opgetree het en getrou het (Boswell 1996:84; Brooten 1996:50-51; Scroggs 1984:147,142).

- Daar is ook getuies op twee ander vase uit die klassieke tydperk gevind wat dui op lesbiese verhoudings. Hier is vroue besig om mekaar se geslagsdele te betas (Brooten 1996: 188-197; Scroggs 1984:143; Smith 1996:241).

- ' $n$ Agaïese vaas (uit die omstreke van Korinte) wat uit ongeveer 620 vC dateer dui op twee vroue wat aan mekaar se gesigte raak. Hul liggaamshouding dui op intimiteit (Smith 1996:241).

- Alkman, 'n digter van Sparta, vertel van die wonderlike liefde tussen twee jonger vroue, Agido en Hagesichora, wat in terme van vandag as ' $\mathrm{n}$ huweliksverhouding beskryf sou kon word (Smith 1996:241).

- Selfs Rabbynse literatuur het kennis gedra van lesbiese verhoudings. Die Sifra is 'n Rabbynse kommentaar op Lev 18 
waarvolgens Moses se lering impliseer dat die Israeliete enige homoseksuele huwelike (manlik én vroulik) sal vermy (Brooten 1996b:61-87; Smith 1996:240).

- Net so word in die Jerusalemse Talmud "n debat tussen die skole van Hillel and Shammai gevind oor die vraag of lesbiese seksuele verhoudings ' $n$ vrou se maagdelikheid wegneem (Brooten 1996b:64-65; Smith 1996:242).

Terug by Paulus: geleerdes is nie eenstemmig oor die datering van Paulus se dood nie. Daar is wel konsensus dat Nero Paulus laat onthoof het. Die datering van Paulus se dood word gegee as tussen 64 nC en 67 nC (Van der Watt 2003:702, 805). Daar kan waarskynlik nie twyfel wees dat Paulus (ook as stoïsynse filosoof) dus kennis gedra het van beide lesbiese- en homoseksuele verhoudings van liefde en trou gedurende sy tyd nie. Dit verklaar waarom Paulus in Romeine 1 spesifiek na manlike en vroulike vorms van homoseksuele verhoudings as para f usin verwys, sowel as die gebruik van die twee Griekse begrippe malako (vroulike homoseksuele persoon) en arsenokoitai (manlike homoseksuele persoon) in 1 Korintiërs 6:9.

Vervolgens dan, 'n beoordeling:

\section{3 'N BEOORDELING}

Die argument wat voorstanders van homoseksuele verhoudings van liefde en trou gebruik dat die destydse antieke en Mediterreense mense nie van sulke verhoudings of identiteite kennis gedra het nie, kan dus nie gehandhaaf word nie. Binne die antropologie van die destydse Mediterreense mense het iemand se optrede, sy/haar identiteit bepaal. Wanneer iemand dus die rol van die vroulike of manlike homoseksuele party vertolk het, was die persoon se identiteit homoseksueel. Die voorkoms van permanente homoseksuele verhoudings van liefde en trou onder die filosowe onderskryf ook my argument. Dat getuienis gevind is van permanente homoseksuele verhoudings van liefde en trou en/of "homoseksuele huwelike" tussen homoseksuele persone (manlik of vroulik) in Rome, Korinte en Efese beteken dat Paulus waarskynlik na sulke permanente homoseksuele verhoudings in sy briewe aan die betrokke gemeentes verwys. Dit kan dus nie meer geargumenteer word dat die Bybelskrywers slegs perversiteit, pederastie of kultiese homoseksuele verhoudings in gedagte gehad het nie. Dié bevindinge behoort 'n 
bepalende rol in die debat rakende die Skriftuurlike verantwoording van permanente homoseksuele verhoudings te speel.

\section{Literatuurverwysings}

Anthonissen C \& Oberholzer P 2001. Gelowig en Gay?. Wellington: Lux Verbi.BM.

Aristoteles 1995. Generation of animals. Santa Monica: World Library.

-, 2000. Nicomachanaen Ethics. Perseus Project - Harvard University Press.

Barnard R 2000. Dis tyd dat Christene anders dink en praat oor seks. Wellington: Hugenote Uitgewers.

Boswell J 1996. Christianity, social Tolerance, and Homosexuality. Chicago: The University of Chicago Press.

Brooten B J 1996. Love between Women. Chicago: University of Chicago.

-, 1985. "Pauls's Views on the Nature of Women and Female Homoeroticism". Immaculate and Powerful: The Female in Sacred Image and Social reality. 1985b.

Christian Reformed Church in North America 1973/1999. Pastoral Care For Homosexual Members.

Huppert C 1988. "Greek love: Homosexuality or Pederstiy? Greek Love in the Black Attic Figures Vase-Painting”. Proceedings of the Third Symposium on Ancient Greek and Related Pottery.

Karros R M 2001. Active/Passive, Acts/Passions: Greek and Roman Sexuality. American Historical Review, Vol. 105 Issue 4, 1255-1261.

Konsepverslag van die SKLAS vir voorlegging aan die Sinode van Wes-enSuid-Kaapland 1999. Homoseksualisme, Ongepubliseer uit argief van die Kommissie vir Leer en Aktuele Sake van die NGK.

Liddel \& Scott 1983. Greek-English Lexicon. Oxford: Claredon Press.

Nussbaum M S 2002. Other Times, Other Places: Homosexuality in Ancient Greece. Annual of Psychoanalysis , Vol. 30, 16-19.

Malina B J 1986. Christian Origins and Cultural Anthropology. Atlanta: John Knox Press.

Plato 1995. Symposiums, - The Greek Philosophers. Santa Monica: World Library.

-, 1995. Seventh Letter, - The Greek Philosophers. Santa Monica: World Library.

-, 1995. Laws - The Greek Philosophers. Santa Monica: World Library.

Scroggs R 1984. The New Testament and Homosexuality, Philadelphia: Fortress Press. 
SKLAS Nederduitse Gereformeerde Kerk Wes-en-Suid-Kaapland 24-25 Maart 2004. Psigiater voordrag tydens bespreking en vrae. Picardie Gastehuis.

Smith M D 1996. Ancient Bisexuality and the interpretation of Romans 1:2627*. Journal of the American Academy of Religion LXIV/2, 234, 240-242.

Van der Watt J G (red.) 2003. Die Bybel A-Z. Vereeniging: Christelike Uitgewersmaatskappy.

Verslag van die kommissie Leer en Aktuele sake van die Sinode van Noordkaapland Mei 2003. Homoseksualiteit: ' $n$ Christelike besinning.

O'Via D 2003. The Bible, the Church and Homosexuality. Minneapolis: Fortress Press.

Werkgroep in verband met homoseksualiteit van die Sinode van die Nederduitse Gereformeerde Kerk van Oos-Transvaal 28 Julie 2001. Gesprek met die lidmate van die Reformerende Kerk en ander persone van homoseksuele oriëntasie. Sinodehuis Pretoria.

Quast K 1994. Reading Corinthian Correspondence - an Introduction. Mahwah: [Paulist Press]. 